\title{
Sensitivity and specificity of five malaria rapid diagnostic kits used in south-south region of Nigeria
}

\author{
Seto Aladenika ${ }^{1}$, Mirabeau Tatfeng ${ }^{2}$, Gilbert Nwobu ${ }^{1}$, Eguagie Osakue ${ }^{3}$, Alfred Ehiaghe ${ }^{1}$, \\ Joy Imuetinya Ehiaghe ${ }^{4}$, Maureen Uchechukwu Okwu' ${ }^{1}$, Augustina Isioma Ikusemoro ${ }^{1}$ \\ ${ }^{1}$ Igbinedion University Okada, Okada, Nigeria \\ ${ }^{2}$ Niger Delta University, Wilberforce Island, Nigeria \\ ${ }^{3}$ Igbinedion University Teaching Hospital Okada, Okada, Nigeria \\ ${ }^{4}$ Laho Medical Center, Benin City, Nigeria \\ Email: setoalade@yahoo.com, youtchou@yahoo.com, osakueosareniro@yahoo.com, fredleo2547@yahoo.com, \\ mokwus@gmail.com, isiotyn@yahoo.com
}

Received 27 September 2012; revised 22 October 2012; accepted 29 October 2012

\begin{abstract}
Sensitivity and specificity of five commonly used rapid malaria test kits in South-South geopolitical zone of Nigeria were analyzed, namely Plasmotest (Biotech International, Germany), Malariatest (Acon Diagnostic, USA), AcumPF (Acumen, China), PF test (Diaspot, Indonesia) and Malaria P.f. (Global, USA). A total of 200 positive malaria blood sample using microscopy as gold standard and 200 negative were obtained from adult and children. All the kits were tested against these gold standards as directed by the manufacturers. Of the 100 positive gold standard used from children sample, $96 \%$ sensitivity were recorded for Biotech, Acon and Global 97\%, while Acumen and Diaspot had $\mathbf{9 9 \%}$ and $98 \%$ respectively. The the highest Specificity was recorded with Biotech 99\% both Acumen and Diaspot had $\mathbf{9 7 \%}$ specificity. In adult blood sample, there was general reduction in the sensitivity of the test kits. We obtained Sensitivity of $30 \%$ with Biotech, $46 \%$ with Acon, Global $73 \%$, Diaspot $75 \%$, and Acumen $78 \%$. Considering the increasing influx of MRDT's into the country, and from the result obtained from this study, there is need for control agensis to ensure that diagnostic test kits be reevaluated before introduction into Nigeria market.
\end{abstract}

Keywords: Malaria; Rapid Malaria Kit; Sensitivity; Specificity

\section{INTRODUCTION}

Malaria is an acute systemic illness caused by infection with Plasmodia species all of which are transmitted to humans by female Anopheles species mosquitoes. Malaria remains one of the leading causes of morbidity and mortality with an estimated 300 to 800 million clinical cases of malaria and 1 to 3 million deaths due to malaria annually in the tropics and subtropics [1]. Malaria kills 1 child every 30 seconds and 3000 children less than 5 years every day [2]. Malaria is the most significant public health problem in Nigeria. It accounts for $25 \%$ of under-5 mortality and $30 \%$ childhood mortality and $11 \%$ maternal mortality [2]. At least $50 \%$ of the population will have at least one episode of malaria annually while children that are aged below 5 years (about 24 million) will have 2 to 4 attacks of malaria annually [3]. Malaria is currently endemic in more than 100 countries worldwide, which in return are visited by more than 125 million travelers annually. P. falciparum is found in subSaharan Africa, Southeast Asia, and the Indian subcontinent as well as in South America, Haiti, the Dominican Republic, Jamaica (where isolated cases have been recently reported), and areas of Oceania [4]. P. malariae and $P$. ovale are present in sub-Saharan Africa. $P$. vivax is prevalent in areas of Southeast Asia, the Indian Subcontinent, and Central and South America [4].

Prompt and accurate diagnosis is key to effective management of malaria. Due to its global impact, the development of diagnostic strategies, that will be effective not only in resource-limited area, where malaria has large burden on society, but also in developed nations, where expertise in malaria diagnosis is often lacking, should be encouraged $[5,6]$. In order to prevent morbidity and mortality, accurate diagnosis of malaria is necessary which will also reduce the misuse of antimalaria. New rapid diagnostic techniques have been developed and evaluated widely in recent years, but the rapid introduction, withdrawal, and modification of commercially available products, variable quality control in manufacturing; and potential decrements in test performance related to the stability of stored test kits have rendered these review largely obsolate [7-9]. 
There is characteristic requirement for a rapid Malaria Diagnostic Test (MRDT) which vary based on regional malaria epidemiology and the goal of malaria control program [10]. The primary goal of Malaria Rapid Diagnostic Tests (MRDTs) should require minimal operator training and yield highly reproducible test interpretation. This method is also seen as a point of care testing which can be done at the bed side of the patient while the physician is actively managing the patient. Though this might not be achievable in all cases, it had been made it clear that the ideal test technique should be able to detect a response to therapy, including detection of recrudescenced or relapse, and stability of its components should be such that refrigeration and cold chain are not needed [11].

The use of malaria rapid diagnostic test kits in our laboratories is on the increase. consequently there is need for the evaluation of this kits. Although data exist on the comparison of serological testing procedures of malaria and microscopy [12], none have focused on the sensitivity and specificity of thses rapid test kits in Nigeria. Against this background this study was aimed at determining the sensitivity and specificity of five malaria rapid kits commonly in Nigeria.

\section{MATERIALS AND METHODS}

\subsection{Study Area}

This work was carried out at Igbinedion University Teaching Hospital, Okada, in Ovia North East Local Government Area of Edo State, between the months of April August 2011, a period that coincides with the rainy season in Nigeria. Okada a rural community is the headquaters of Ovia North East Local Government Area of Edo State which has an estimated population of 155,344 persons [13]. Majority of the dwellers are farmers and traders. Less than $10 \%$ of the population is formed lecturers and students.

\subsection{Selected Kits}

The kits used in this study were the most commonly used and most available in the Nigerian market. The kits are; Plasmotest (Biotech International, Germany), Malariatest (Acon Diagnostic, USA), AcumPF (Acumen, China), PF test (Diaspot, Indonesia) and Malaria P.f. (Global, USA).

\subsection{Study Population}

Blood samples of 200 patients comprising of (100 children and 100 adults), confirmed for the presence of malaria parasite using microscopy method at the Igbinedion University Teaching Hospital, Okada, and were used for this study. A further 200 subjects comprising of (100 children and 100 adults) that were negative for malaria parasite also recruited and served as control. The study was conducted between July and September 2011. Verbal consent was gotten from participating adult subjects, and guardians/wards in cases of children. The etical committee of the Igbinedion University Teaching approved this work.

\subsection{Sample Collection}

Three milliliters $(3 \mathrm{ml})$ of venous blood was collected from each patient and control subject and dispensed into an Ethylene diamine tetra-acetic acid (EDTA) container and gently mixed. The samples were taken immediately to the laboratory for processing.

\subsection{Gold Standard Preparations}

\section{Thick film examination/Parasites count}

Thick films were made from the anti-coagulated blood, allowed to dry and stained using Giemsa stain [14]. The blood films were examined under $\times 100$ microscope objective lens for morphological features of Plasmodium sp. 100 positive samples and negative sample were used as gold standard.

Parasite density was carried out using standard formulae for parasites count as described by Cheesbrough [14].

$$
=\frac{\text { Parasites } / \mu \mathrm{l}}{100}
$$

\subsection{Serological Testing}

The serological diagnosis was carried out using; Plasmotest (Biotech International, Germany), Malariatest (Acon Diagnostic, USA), AcumPF (Acumen, China), PF test (Diaspot, Indonesia) and Malaria P.f. (Global, USA) following the instructions provided by the manufacturers. Except for Acon that is lateral flow others were flow through.

\subsection{Diagnostic Sensitivity and Specificity}

The diagnostic sensitivity and specificity were determined according to World Health Organization Standard [15]. All tests were performed according to the manufacturer's recommendation.

\section{RESULTS}

This study was carried out using 400 blood samples. Two hundred samples were positive by microscopic method and were grouped as positive gold standard. The remaining 200 samples were labeled negative gold standard after they have been confirmed by microscopy. The positive gold standard made up of 100 positive samples from children and 100 positive samples from adults (Tables 1 and 2). 
Table 1. Sensitivity and specificity of the test kit with children samples.

\begin{tabular}{lcccccc}
\hline RDT Kits & True +ve & True -ve & False +ve & False-ve & $\begin{array}{c}\text { Sensitivity } \\
(\%)\end{array}$ & $\begin{array}{c}\text { Specificity } \\
(\%)\end{array}$ \\
\hline Biotech & 96 & 99 & 1 & 4 & 96 & 99 \\
Acon & 97 & 98 & 2 & 3 & 97 & 98 \\
Acumen & 99 & 97 & 3 & 1 & 99 & 97 \\
Diaspot & 98 & 97 & 3 & 2 & 98 & 97 \\
Global & 97 & 98 & 2 & 3 & 97 & 98 \\
\hline
\end{tabular}

Table 2. Sensitivity and specificity of the test kit on samples of adult patients.

\begin{tabular}{lcccccc}
\hline RDT Kits & True +ve & True $-\mathrm{ve}$ & False $+\mathrm{ve}$ & False $-\mathrm{ve}$ & $\begin{array}{c}\text { Sensitivity } \\
(\%)\end{array}$ & $\begin{array}{c}\text { Specificity } \\
(\%)\end{array}$ \\
\hline Biotech & 30 & 99 & 1 & 70 & 30 & 99 \\
Acon & 46 & 98 & 2 & 54 & 46 & 98 \\
Acumen & 78 & 97 & 3 & 22 & 78 & 97 \\
Diaspot & 75 & 96 & 4 & 25 & 75 & 96 \\
Global & 73 & 97 & 3 & 27 & 73 & 97 \\
\hline
\end{tabular}

Table 3. Comparison between sensitivity and specificity of the five MRDT's to adult and children sample.

\begin{tabular}{lcccc}
\hline \multirow{2}{*}{ Kit } & \multicolumn{2}{c}{ Sensitivity } & \multicolumn{2}{c}{ Sensitivity } \\
\cline { 2 - 5 } & Adult & Children & Adult & Children \\
\hline Biotech & 30 & 96 & 99 & 99 \\
Acon & 46 & 97 & 98 & 98 \\
Acumen & 78 & 99 & 97 & 97 \\
Diaspot & 75 & 98 & 96 & 97 \\
Global & 73 & 97 & 97 & 98 \\
\hline
\end{tabular}

Table 4. Malaria parasite load in positive gold standard blood sample from children and adult.

\begin{tabular}{lcccc}
\hline & $<600$ parasite $/ \mu 1$ & $600-6000$ parasite $/ \mu 1$ & $>6000$ parasite $/ \mu 1$ & Total \\
\hline Children & 30 & 34 & 36 & 100 \\
Adult & 40 & 41 & 19 & 100 \\
\hline
\end{tabular}

The sensitivity and specificity of the test kits using children sample revealed that Biotech had a sensitivity and specificity of $96 \%$ and $99 \%$ respectively, Acon had a sensitivity and specificity of $97 \%$ and $98 \%$, Diaspot, $98 \%$ sensitivity and $97 \%$ specificity (Table 1).

The sensitivity and specificity of the test kits using adult sample revealed that Biotech had a sensitivity and specificity of $30 \%$ and $99 \%$ respectively, Acumen had a sensitivity and specificity of $78 \%$ and $97 \%$, Diaspot, $75 \%$ sensitivity and $96 \%$ specificity (Table 2). There was significant difference in sensitivity of the kits to adult sample compared with children sample $(\mathrm{P}<0.05)$ (Table 3).

Thirty six percent (36\%) of children and $19 \%$ of adult had parasite load above 6000 parasite/ $\mu 1,34 \%$ (children) and $41 \%$ (adult) had the parasite load ranging between 601 and 6000 while $30 \%$ and $40 \%$ of children and adult respectively had parasite load less than 600 parasite/ $\mu 1$ (Table 4).

The accuracy of the five MRDT's evaluated using 
children blood were found to be 0.975 except for Acumen having 0.980 accuracy (Table 5). Biotech also had the lowest false posive rate of 0.01 as in children sample but false negative rate increased from 0.04 in childrens sample to 0.70 in adult. Generally, higher false negative rate were found in adult sample. Each of the kits have different accuracy but Acumen still remain the Kit with the highest accuracy of 0.875 (Table 6).

\section{DISCUSSION AND CONCLUSION}

In order to alleviate the expanding impact of malaria across the globe, as well as its associated increasing drug resistance, establishment of prompt and accurate diagnosis is required. Microscopy has been seen as gold standard for malaria diagnosis especially in under developed nation, but in recent years, a number of new techniques have become available for the diagnosis of malaria infection. Since the World Health Organization (WHO) recognized the urgent need for new, simple, quick, accurate, and cost-effective diagnostic tests for determining the presence of malaria parasites, to overcome the deficiencies of light microscopy, numerous new malaria-diagnostic techniques have been developed [16]. One of the techniques is the Malaria Rapid Diagnostic Technique its low complexity invites their use by people without formal medical laboratory training for self-diagnosis suggested that HRT-2 based RTD's can be employed successfully by village volunteers with minimal training [17]. However, in this part of the nation where the climatic conditions and environment favour the malaria vector (Anopheles mosquito), there is need for urgent diagnosis, of which MRDT's tends to provide. This present study demonstrated a variation in sensitivity of the MRDT's to adult and children with malaria infection. Unlike previous analysis done by Gasser and his colleagues [18], which they reported that there is no significant difference in sensitivity of the test kit as par age difference. Our present findings revealed that the kits are more sensitive in children malaria compared to adults. For instance, Acumen which shows the highest sensitivity of $99 \%$ in children had $78 \%$ sensitivity with adult blood sample of positive gold standard Furthermore, it was found out that the detection rate of other rapid Malaria Kit which is an antigen test had a higher performance in children than in adult. This finding is in accordance with the work of Tatfeng and Bawo [19] who reported that rapid Malaria Combo Diagnostic Kit had higher sensitivity in children than adults. The variation in the sensitivity of this test kits with the age variation may be partially accredited to the fact that the test kit detect malaria parasite antigen rather than antibody. And it has been documented that malaria develop faster in children compared to adults due to the fact that the children erythrocytes are rich in haemoglobin [19].

Table 5. Performance of kits against positive and negative gold standards children blood sample.

\begin{tabular}{lccccc}
\hline MRDT & $\begin{array}{c}\text { False Positive } \\
\text { Rate }\end{array}$ & $\begin{array}{c}\text { False Negative } \\
\text { Rate }\end{array}$ & $\begin{array}{c}\text { Positive } \\
\text { Predictive Value }\end{array}$ & $\begin{array}{c}\text { Negative } \\
\text { Predictive Value }\end{array}$ & $\begin{array}{c}\text { Test } \\
\text { Accuracy }\end{array}$ \\
\hline Biotech & 0.01 & 0.04 & 0.99 & 0.96 & 0.975 \\
Acon & 0.02 & 0.03 & 0.98 & 0.97 & 0.975 \\
Acumen & 0.03 & 0.01 & 0.97 & 0.99 & 0.980 \\
Diaspot & 0.03 & 0.02 & 0.97 & 0.99 & 0.975 \\
Global & 0.02 & 0.03 & 0.98 & 0.97 & 0.975 \\
\hline
\end{tabular}

Table 6. Performance of kits against positive and negative gold standards adult blood sample.

\begin{tabular}{lccccc}
\hline MRDT & $\begin{array}{c}\text { False Positive } \\
\text { Rate }\end{array}$ & $\begin{array}{c}\text { False Negative } \\
\text { Rate }\end{array}$ & $\begin{array}{c}\text { Positive } \\
\text { Predictive Value }\end{array}$ & $\begin{array}{c}\text { Negative } \\
\text { Predictive Value }\end{array}$ & $\begin{array}{c}\text { Test } \\
\text { Accuracy }\end{array}$ \\
\hline Biotech & 0.01 & 0.70 & 0.97 & 0.59 & 0.645 \\
Acon & 0.02 & 0.54 & 0.96 & 0.65 & 0.720 \\
Acumen & 0.03 & 0.22 & 0.96 & 0.82 & 0.875 \\
Diaspot & 0.04 & 0.25 & 0.95 & 0.79 & 0.855 \\
Global & 0.03 & 0.27 & 0.96 & 0.78 & 0.850 \\
\hline
\end{tabular}


The specificity of the test kits were not affected by age. For instance, Biotech shows 99\% specificity and Acon 98\% sensitivity in adults and children. The Biotech shows highest specificity but poorly sensitive to adult malaria $30 \%$. The reduction in sensitivity of the test kits may be due to the fact that all the kits tested were only made for the detection of $P$. falciparum which is the predominant malaria parasite in Nigeria some few cases of $P$. vivax infection which our thick film only show as malaria parasite since the method cannot differentiate species. The reduction in sensitivity of some of these kits may also be due to long storage they experience while shipping them down to the country since they are not being produced here. Base on genetic variation of the $P$. faciparum, there is possibility that some of the false negatives are primarily due to genetic modification of the Plasmodium. The low level or absence of HRP-2 secretion by sexual forms may explain the negative results in some cases [20].

Since Nigeria is one of the countries strongly affected by these deadly diseases, a large meta-analysis of rapid tests for malaria may be effective adjuncts to microscopy in centers without expertise in tropical medicine but that expert microscopy is still needed for species identification and confirmation. Conclusively, considering the increasing influx of MRDT's into the country, and from the result obtained from this study, there is need for control agencies such as National Agency for Food and Drug Administration and Control (NAFDAC) as well as Standard organization of Nigeria (SON) to ensure that diagnostic test kits be reevaluated before introduction into Nigeria market.

\section{REFERENCES}

[1] Guerrant, R.L., Walker, D.H. and Weller, P.F. (2006) Tropical infectious diseases: Principles, patogens and practice. 6th Edition, Elsevier Churchill-Livingstone, Philadelphia, 159.

[2] Tjahjani, S., Puji, B.S.A., Syafruddin, D., Agoes, R., Hanggono, T. and Immaculata, M. (2008) Oxidative stress in plasmodium falciparum culture incubated with artemisinin. Proceedings of the Third ASEAN Congress of Tropical Medicine and Parasitology, 3, 47-50.

[3] WHO (2008) Malaria. http://www.who.int/countries/nga/areas/malaria/en/index. html

[4] CDC (2009) Malaria. Centers of Disease Control and Prevention, Atlanta.

http://www.cdc.gov/travel/diseasePs.htm\#malaria (Date accessed 26/4/2009)

[5] Bell, D., Wongsrichanalai, C. and Barnwell, J.W. (2006) Ensuring quality and access for malaria diagnosis: How can it be achieved? Nature Reviews Microbiology, 4, S7S20. doi: $10.1038 /$ nrmicro 1525
[6] Reyburn, H., Mbakilwa, H., Mwangi, R., Mwerinde, O., Olomi, R., Drakeley, C. and Whitty C. J. (2007) Rapid diagnostic tests compared with malaria microscopy for guiding outpatient treatment of febrile illness in tanzania: Randomised trial. British Medical Journal, 334, 403. doi:10.1136/bmj.39073.496829.AE

[7] Marx, A., Pewsner, D., Egger, M., Nüesch, R., Bucher, H.C., Genton, B., Hatz, C. and Jüni, P. (2005) Metaanalysis: Accuracy of rapid tests for malaria in travelers returning from endemic areas. Annals of Internal Medicine, 142, 836-846.

[8] Moody, A. (2002) Rapid diagnostic tests for malaria parasites. Clinical Microbiology Reviews, 15, 66-78. doi:10.1128/CMR.15.1.66-78.2002

[9] Murray, C.K., Bell, D., Gasser, R.A. and Wongsrichanalai, C. (2003) Rapid diagnostic testing for malaria. Tropical Medicine and International Health, 8, 876-883. doi:10.1046/j.1365-3156.2003.01115.x

[10] Bell, D. and Peeling, W.R. (2006) Evaluation of rapid diagnostic tests: Malaria. Nature Reviews Microbiology, 4, S34-S38. doi:10.1038/nrmicro1524

[11] WHO and Western Pacific Region (2006) Towards quality testing of malaria rapid diagnostic tests: Evidence and methods. Manila, Philippines.

[12] Amadi, E.C., Ebenezer, A. and Daworiye, P.S. (2010) Comparison of rapid malaria test and laboratory microscopy investigation for community-based active surveillance of asymptomatic falciparum malaria in Yenagoa, Niger Delta, Nigeria. Journal of Applied Sciences and Environmental Management, 14, 71-74.

[13] National Population Commission (2006) Population and housing census of the federal republic of Nigeria. http://www.population.gov.ng/

[14] Cheesbrough, M. (2000) Malaria parasites. In: Medical laboratory manual for tropical countries. 2nd Editon, 2, 221-245.

[15] WHO/LAB (1998) Quality assurance in Haematology. World Health Organization, Geneva, WHO/LAB/98.4, 10.

[16] WHO (1996) WHO information consultation on recent advances in diagnostic techniques and vaccines for malaria: A rapid dipstick antigen capture assay for the diagnosis of falciparum malaria. Bulletin of the World Health Organization, 74, 47-54.

[17] Carrara, V.I., Sirilak, S., Thonglairuam, J., Rojanawatsirivet, C., Proux, S., Gilbos, V., Brockman, A., Ashley, E.A., McGready, R., Krudsood, S., Leemingsawat, S., Looareesuwan, S., Singhasivanon, P., White, N. and Nosten, F. (2006) Deployment of early diagnosis and mefloquine-artesunate treatment of falciparum malaria in Thailand: The Tak Malaria Initiative. PLOS Medicine, $\mathbf{3}$, e183. doi:10.1371/journal.pmed.0030183

[18] Gasser Jr., R.A., Magill, A.J., Ruebush, T., Miller, R.S., Sirichaisinthop, J., Forney, J.R., Bautista, C.T., Arevalo, I., Rhorer, J., Wittes, J. and Wongsrichanalai, C. (2005) Malaria diagnosis: Performance of NOW ICT Malaria in a large scale field trial. The 54th Annual Meeting of the American Society of Tropical Medicineand Hygiene, 2338. 
[19] Tatfeng, Y.M. and Bawo, D. (2008) Malaria diagnosis in Nigeria: Of what relevance is malaria combo rapid diagnostic kit? African Journal of Applied Zoology and Environmental Biology, 10, 24-26.

[20] Brenier-Pinchart, M.P., Pinel, C., Croisonnier, A., Brion, J.P., Faure, O., Ponard, D. and Ambroise-Thomas, P.
(2000) Diagnosis of malaria in non-endemic countries by the Parasight-F test. The American Journal of Tropical Medicine and Hygiene, 63, 150-152. 